EESTI NSV TEADUSTE AKADEEMIA TOIMETISED. 28. KOIDE

KEEMIA. 1979, NR. 2

ИЗВЕСТИЯ АКАДЕМИИ НАУК ЭСТОНСКОЙ ССР. ТОМ 28 Химия. 1979, 스 2

К. УРОВ, И. НЕЧАЕВ, А. ЯАНУС

удК $553.983 .002 .61(474)$

\title{
О ВЛИЯНИИ КОНЦЕНТРИРОВАННЫХ КИСЛОТ НА СОСТАВ И СВОЙСТВА КЕРОГЕНА (НА ПРИМЕРЕ КУКЕРСИТА)
}

\author{
Представлена О. Эйзеном
}

Для углубленного исследования нерастворимой части органического вещества (OB) осадочных пород, в том числе нефтематеринских, необходимо выделение ОВ в концентрированном виде. Наиболее распространенный и эффективный метод получения концентратов керогена, широко применяющийся в лабораториях битуминологического профиля как в СССР $\left[{ }^{1-3}\right]$, так и за рубежом $\left[{ }^{4}\right],-$ это обработка породы концентрированными хлористо- и фтористоводородной кислотами. Имеются данные $\left[{ }^{5-10}\right]$, что ОВ при этом претерпевает определенные изменения, однако вопрос о характере и масштабах влияння кислотной обработки на состав керогена еще далеко не ясен. В случае пород с низкой концентрацией ОВ сравнительный анализ керогена до и после кислотной обработки затруднителен, так как преобладающая в исходной породе минеральная часть искажает результаты определения ряда характеристик ОВ (элементный состав, инфракрасные спектры и др.).

В настоящей работе приведены результаты исследования влияния концентрированных соляной и плавиковой кислот на флотационный концентрат сланца-кукерсита $(89 \%$ OВ); вследствие низкого содержания минеральных компонентов их наличие мало сказывается на результатах анализа ОВ.

Кислотная обработка проводилась в наиболее жестком режиме [[ $\left.{ }^{4}\right]$ с трехкратным выпариванием смеси концентрированных соляной и плавиковой кислот из суспензии со сланцем. Экстракцию образцов хлороформом осуществляли в аппарате Сокслета в течение 20 ч. Для получения сравнительных данных о влиянии обработки кислотами на выход и состав продуктов термического разложения керогена, отражающих особенности химического строения ОВ, проводили полукоксование сланца в алюминиевой реторте по ГОСТ 3168-66. Полученные смолы обесфеноливали 10\%-ным раствором гидроокиси натрия, обесфеноленные смолы разделяли на групповые компоненты методом тонкослойной хроматографии по методике [11] на силикагеле. Газохроматографический анализ битумоидов и смол проводили на аппарате Хром-4 с применением набивных и капиллярных колонок различной полярности в условиях программирования температуры. Состав газов термической деструкции определяли также газохроматографически [ $\left.{ }^{12}\right]$. Инфракрасные спектры снимали на приборе UR-10 в таблетках из бромистого калия.

Выход продукта кислотной обработки составил 98,6\% (по ОВ), от исходного концентрата он отличался более темной окраской. Характе- 


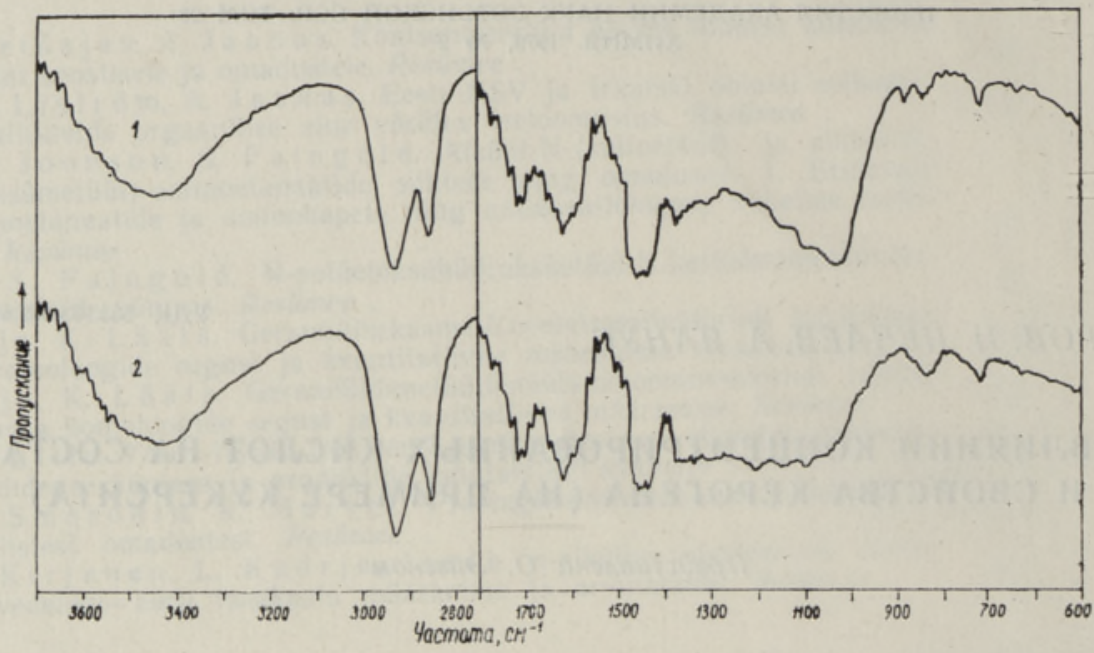

Рис. 1. Инфракрасные спектры исходного (I) и обработанного (2) концентрата кукерсита.

Характеристика концентратов кукерсита

Таблица 1 до и после обработки концентрированными кислотами

\begin{tabular}{|c|c|c|}
\hline Показатели & $\begin{array}{c}\text { До } \\
\text { обработки }\end{array}$ & $\begin{array}{c}\text { После } \\
\text { обработки }\end{array}$ \\
\hline $\mathrm{W}^{\mathrm{a}}$, вес. $\%$ & 1,2 & 2,0 \\
\hline $\begin{array}{l}\text { На сухое вещество, вес. \%: } \\
\text { Ac }^{\text {c }} \text { : }\end{array}$ & 10,1 & 2,5 \\
\hline $\mathrm{y}_{\text {глекислота карбонатов }\left(\mathrm{CO}_{2}\right)^{\mathrm{c}}}$ & 0,9 & 0 \\
\hline Условная органическая масса $\left[100-\mathrm{A}^{\mathrm{c}}-\left(\mathrm{CO}_{2}\right)^{\mathrm{c}}\right]$ & 89,0 & 97,5 \\
\hline $\begin{array}{l}\text { На органическое вещество: } \\
\text { Элементный состав, вес. \%: }\end{array}$ & & \\
\hline $\begin{array}{c}\text { Элементный состав, вес. \%: } \\
\text { Углерод }\end{array}$ & 77,7 & 76,7 \\
\hline Водород & 9,4 & 9,1 \\
\hline Хлор + фтор (в пересчете на хлор) & 0,6 & 1,5 \\
\hline Кислород + сера + азот (по разности) & 12,2 & 12,7 \\
\hline Отношение $\mathrm{H} / \widehat{\mathrm{C}}$ (атом.) & 1,45 & 1,42 \\
\hline Выход хлороформенного экстракта, вес. \% & 0,90 & 1,22 \\
\hline Теплота сгорания по бомбе, ккал/ке & 8830 & 8520 \\
\hline Выход продуктов полукоксования, вес. \%: & & \\
\hline $\begin{array}{l}\text { Смола } \\
\text { Вода разложения }\end{array}$ & $\begin{array}{r}05,0 \\
5,5\end{array}$ & $\begin{array}{r}04,0 \\
5,5\end{array}$ \\
\hline Полукокс & 14,0 & 16,4 \\
\hline Газ + потери & 14,7 & 13,5 \\
\hline
\end{tabular}

ристика кукерсита до и после обработки кислотами приведена в табл. 1, инфракрасные спектры - на рис. 1.

ИК-спектры исходного и обработанного концентрата в основных чертах подобны. Наиболее заметные изменения в них - уменьшение интенсивности полос поглощения $1000-1070$ (силикаты) и $880 \mathrm{~cm}^{-1}$ (карбонаты) - закономерны. Наряду с этим, в спектре обработанного кислотами кукерсита несколько усиливается поглощение в области 1200-1370 $\mathrm{cm}^{-1}$, обусловленное, возможно, фторсодержащими соединениями, и изменяется относительная интенсивность полос $1430-1470$ и $1590-1640 \mathrm{~cm}^{-1}$, хотя их форма и тонкая структура сохраняются.

Из данных табл. 1 явствует, что обогащению кислотами сопутствуют 


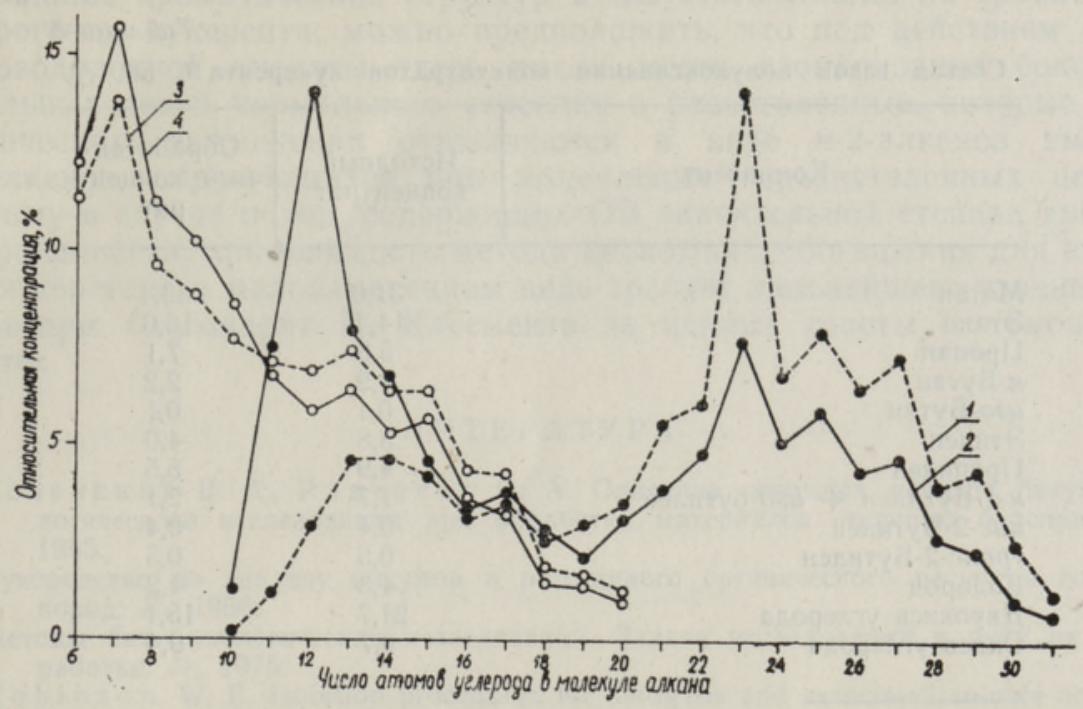

Рис. 2. Распределение по длине цепи $н$-алканов в битумоиде $(1,2)$ и смоле полукоксования $(3,4)$ исходного $(1,3)$ и обработанного кислотами $(2,4)$ концентрата кукерсита.

Таблица 2

Характеристика смол полукоксования концентрата кукерсита

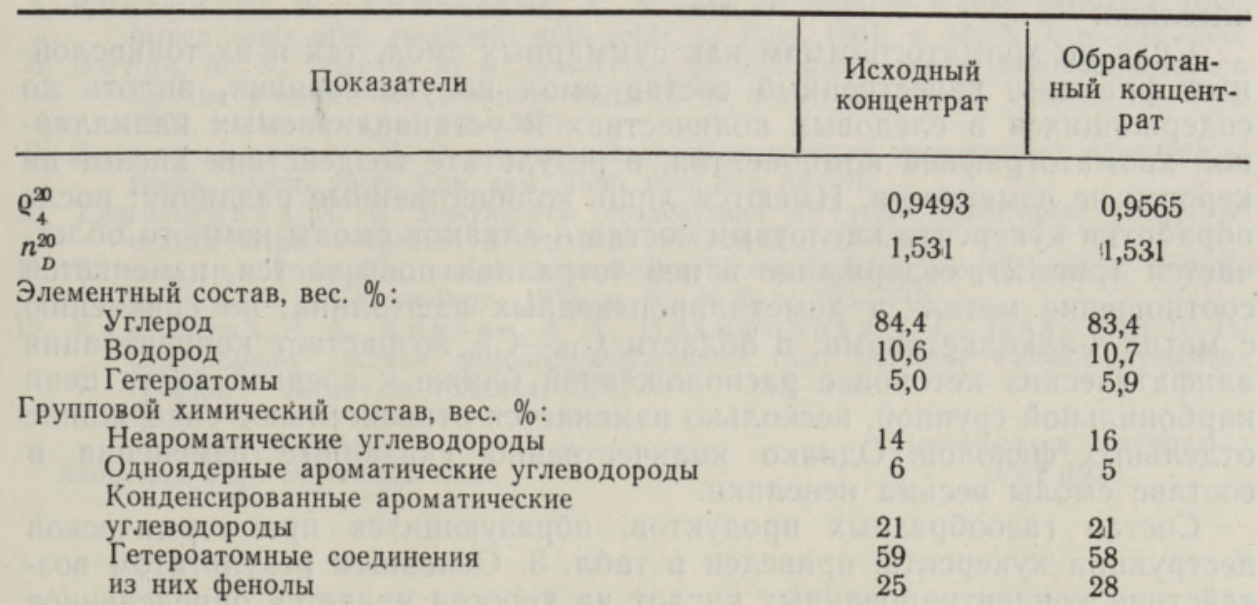

относительно небольшие изменения в содержании углерода и водорода в ОВ и его теплотворности (1,3-3,5 \% отн.), мало меняется и такой чувствительный показатель, как выход смолы полукоксования. Содержание галогенов в керогене несколько возрастает. Выход хлороформенного битумоида под действием кислот увеличивается с 0,9 до $1,2 \%$ на ОВ. Газохроматографический анализ показал, что максимум на кривой распределения $н$-алканов битумоида по длине цепи при этом смещается: от $\mathrm{C}_{23}$ до $\mathrm{C}_{12}$ (рис. 2). Следовательно, в результате воздействия кислот образуется дополнительное количество алканов с более короткой цепью, хотя, учитывая низкий абсолютный прирост количества битумоида, масштаб новообразования углеводородов незначителен. 
Таблица 3

Состав газов полукоксования концентратов кукерсита *, об. \%

\begin{tabular}{l|c|c}
\hline \multicolumn{1}{c|}{ Компонент } & $\begin{array}{r}\text { Исходный } \\
\text { концентрат }\end{array}$ & $\begin{array}{r}\text { Обработан- } \\
\text { ный концент- } \\
\text { рат }\end{array}$ \\
\hline Метан & 31,0 & 33,4 \\
Этан & 14,4 & 16,0 \\
Пропан & 5,6 & 7,1 \\
н-Бутан & 1,9 & 2,2 \\
изо-Бутан & 0,1 & 0,1 \\
Этилен & 3,8 & 4,0 \\
Пропилен & 4,9 & 5,5 \\
н-1'-Бутилен + изо-бутилен & 1,7 & 2,1 \\
цис-2-Бутилен & 0,4 & 0,4 \\
транс-2-Бутилен & 0,5 & 0,5 \\
Водород & 4,3 & 4,2 \\
Двуокись углерода & 21,7 & 15,1 \\
Окись углерода & 9,7 & 9,4
\end{tabular}

* Кроме сероводорода (не определяли).

В табл. 2 приведена характеристика смол полукоксования исходного и обработанного кислотами концентрата кукерсита. В отличие от битумоидов, состав смолы отражает химическое строение подавляющей части ОВ сланца, но и здесь аналитические показатели меняются незначительно.

Судя по хроматограммам как суммарных смол, так и их тонкослойных фракций, качественный состав смол полукоксования, вплоть до содержащихся в следовых количествах и устанавливаемых капиллярной хроматографией компонентов, в результате воздействия кислот на кероген не изменяется. Имеются лишь количественные различия: после обработки кукерсита кислотами состав $\boldsymbol{\mu}$-алканов смолы немного облегчается (рис. 2), содержание в ней тетралина повышается, изменяется соотношение метил- и диметилпроизводных нафталина, по сравнению с метил-н-алкилкетонами, в области $\mathrm{C}_{10}-\mathrm{C}_{15}$ возрастает концентрация алифатических кетонов с расположенной ближе к средней части цепи карбонильной группой, несколько изменяется относительное содержание отдельных фенолов. Однако количественно указанные изменения в составе смолы весьма невелики.

Состав газообразных продуктов, образующихся при термической деструкции кукерсита, приведен в табл. 3. Основным результатом воздействия концентрированных кислот на кероген является определенное уменьшение образования двуокиси углерода.

В целом полученные данные свидетельствуют о том, что в случае богатого водородом, преимущественно неароматического кукерсита обогащение концентрированными соляной и плавиковой кислотами не приводит к глубоким изменениям в составе и свойствах керогена. При обогащении по этой же методике диктионемового сланца ЭССР *, вследствие высокой зольности которого достаточно точное сравнение состава ОВ исходного и обработанного сланца оказалось невозможным, в составе алифатических углеводородов смолы полукоксования продукта кислотной обработки было обнаружено значительно больше H-2-алкенов, чем в смоле из исходного сланца. Учитывая более высокое

* Обогащение диктионемового сланца проводила Ю. Риккен. 
содержание ароматических структур в ОВ этого сланца по сравнению с керогеном кукерсита, можно предположить, что под действием фтористоводородной кислоты здесь имела место изомеризация боковых алкильных цепей нормального строения в разветвленные, которые при термическом разложения отщепляются в виде $\boldsymbol{H}$-2-алкенов вместо $H$-1-алкенов, образующихся при отщеплении неразветвленных цепей. Поэтому в случае пород, содержащих ОВ значительной степени ароматизированности, применимость метода кислотного обогащения для выделения керогена в малоизмененном виде требует дальнейшего уточнения.

Авторы благодарят И. Клесмента за ценные советы и помощь в работе.

\section{ЛИТЕРАТУРА}

1. Успенский В. А., Р ад ченко О. А. Описание основных методов битуминологического исследования при обработке материалов опорного бурения. Л., 1955.

2. Руководство по анализу битумов и рассеянного органического вещества горных пород. Л., 1966.

3. Методы битуминологических исследований. Задачи исследований и пути их разработки. Л., 1975.

4. Ro bi n s o n, W. E. Isolation procedures for kerogens and associated soluble organic materials. - In: Organic geochemistry. Methods and results. Berlin, Heidelberg, New York, 1969 , p. 181-195.

5. Hentze, E. Ober die Möglichkeit aus bituminösen Gesteinen das Bitumen in seiner ursprünglichen Form zu isolieren. - Z . angew. Chem., 1922, Bd. 35, N 6, S. $330-331$.

6. Gaertner, H. R., Kroepelin, H. Petrographische und chemische Untersuchungen von Posidonienschiefer Nordwestdeutschlands. - Erdöl und Kohle, 1956, Bd. 9 , N 10, S. $680-682$.

7. Kuczynski, W., Andrzejak, A. A note on organic matter extracted from brown coals after treatment with acids. - Fuel, 1961, v. 40, N 3, p. 203-206.

8. Burns, M. S., Durie, R. A., S w a in e, D. J. Significance of chemical evidence for the presence of carbonate minerals in brown coals and lignites. - Fuel, 1962 , v. 41 , N. 4 , p. $373-383$.

9. 3 а шк ил вн я к M. М. О деминерализации карпатских менилитовых сланцев. Вестн. Львов. ун-та. Сер. хим., 1965, вып. 8, с. 88-91.

10. Т еребенни а А. В. Результаты воздействия на уголь некоторых кислот в едкого натра. - Химия тв. топлива, 1971, № 2, с. 11-16.

11. Klesment, I. Application of chromatographic methods in biogeochemical investigations. - J. Chromatogr., 1974, v. 91, N 2, p. 705-713.

12. Коняшина Р. А., Кричко А. А., Никифорова Т. С., Пахомов В. П. Определение состава водородсодержащего газа методом газовой хроматографии. - Химия тв. топлива, 1970, № 4, с. 135-138.

Ннститут химии

Академии наук Эстонской ССР
Поступила в редакцию $8 / \mathrm{VI} 1978$

\section{KONTSENTREERITUD HAPETE TOIMEST KUKERSIIDI KEROGEENI KOOSTISELE JA OMADUSTELE}

Artiklis on esitatud järeldus, et vesinikurikka, pōhiliselt mittearomaatse kukersiidi puhul orgaanilise aine eraldamiseks rakendatav kontsentreeritud mineraalhapetega töötlemise meetod ei muuda oluliselt kerogeeni koostist. Rohkem aromatiseerunud diktüoneemakilda puhul võib seejuures täheldada môningat kōrvalahelate isomeriseerumist. 
K. UROV, I. NECHAYEV, A. JAANUS

\section{ON THE EFFECT OF CONCENTRATED ACIDS ON THE COMPOSITION AND PROPERTIES OF KEROGEN (ON THE BASIS OF KUKERSITE-SHALE)}

In the case of the hydrogen-rich, mainly non-aromatic kerogen of kukersite-shale, the treatment with concentrated mineral acids (a method for the isolation of organic matter) does not call forth any substantial changes in the composition of the kerogen. Some data obtained indicate that aliphatic chains in the more aromatizied kerogen of dictyonema shale undergo some isomerization during treatment. 